\title{
Escola Vista de Fora: 0 que dizem as famílias?
}

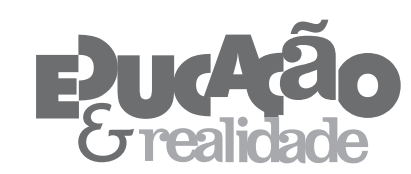

Luana Costa Almeida'

Luana Ferrarotto"

Maria Marcia Sigrist Malavasi"I

'Universidade do Vale do Sapucaí (UNIVAS), Pouso Alegre/MG - Brasil "Instituto Federal de Educação, Ciência e Tecnologia de São Paulo (IFSP),

Bragança Paulista/SP - Brasil

"'Universidade Estadual de Campinas (UNICAMP), Campinas/SP - Brasil

RESUMO - Escola Vista de Fora: o que dizem as famílias? O artigo objetiva analisar a visão expressa nas falas das famílias, sobre a escola de seus filhos. Analisam-se as respostas abertas de questionários respondidos em quatro escolas municipais de Campinas-SP, eleitas pelo critério de contraste: maior e menor nível socioeconômico. $\mathrm{Na}$ análise foram considerados os temas Qualidade do Ensino; Relacionamento escola-comunidade; Organização escolar; Razões da apreciação da escola; Atividades extraturno; Segurança. Percebe-se uma visão diferencial da escola relacionada à classe social e que ouvir as famílias permite conhecer o lugar ocupado pela escola em suas vidas, elucidando aspectos nem sempre claros aos profissionais que, se considerados, podem contribuir com a trajetória escolar dos estudantes.

Palavras-chave: Família. Escola. Qualidade Educacional. Relação Escola-Família.

ABSTRACT - School Seen from Outside: what do the families say? The article aims at analyzing the view expressed in families' discourse regarding their children's school. Open answers from questionnaires filled in four municipal schools from Campinas, São Paulo state, elected by contrast criteria (higher or lower social-economic level) are analyzed. For this analysis, the topics of Education Quality; School-Community Relationship; School Organization; Reasons for School Appreciation; Extra-class Activities; and Security were considered. It is possible to observe a differential view towards school related to social class and that listening to the families allows for knowing the place occupied by the school in their lives, elucidating aspects which are not always clear to professionals that, when considered, can contribute to the students' school life. Keywords: Family. School. Educational Quality. School-Family Relationship.

Educação \& Realidade, Porto Alegre, v. 42, n. 2, p. 649-671, abr./jun. 2017. 649 http://dx.doi.org/10.1590/2175-623656159 


\section{Introdução}

A participação da família no processo de escolarização dos filhos tem sido cada vez mais considerada nas discussões das trajetórias escolares das crianças. Tal participação, em suas diversas formas, tornou-se uma categoria explicativa de parte importante do rendimento escolar dos estudantes.

Em estudos de diferentes abordagens temos visto a associação de aspectos familiares a desfechos educacionais vivenciados pelos alunos, seja em termos de desempenho e sua relação com a origem socioeconômica do estudante (Coleman, 1966; Nogueira et al., 2009; Solis, 2008; Travitzki, 2013, dentre outros), seja pelas ações praticadas na família e seus modelos de socialização que facilitam ou não o processo escolar vivenciado por seus filhos na escola (Müller; Paixão, 2006; Grolnick; Slowiaczek, 1994; dentre outros).

O debate acerca do modo como se concretiza a relação escola-família faz-se necessário para o aprimoramento dos trabalhos realizados junto às crianças. Na reflexão acerca dessa relação, vale destacar que, assim como verifica-se associação entre nível socioeconômico e desempenho escolar, autores como Nogueira (2006), Lomonaco e Garrafa (2009) e Silva (2009), advertem que há, também, uma interdependência entre condições sociais das famílias e suas formas de envolvimento com a escola.

Em estudo de levantamento bibliográfico em produções nacionais, Almeida e Betini (2015) observaram que muitas pesquisas posicionam a escola como fornecedora de orientações a serem seguidas pelas famílias, portanto tal relação nem sempre ocorre em um nível de igualdade. Esta assimetria pode ser compreendida pelos lugares diferentes ocupados por família e escola, em que a instituição escolar possui um status de poder quanto à educação dos alunos, direcionando as ações esperadas dos pais/responsáveis.

Observa-se, ainda, dificuldades na comunicação entre as partes, “[...] as quais não conseguem estabelecer um diálogo claro, seja em relação às suas atitudes quanto às crianças (orientações), seja em relação aos papéis a desempenhar" (Almeida; Betini, 2015, p. 46). Aspecto em que aparentemente, de acordo com Oliveira e Marinho-Araújo (2010, p. 104), há uma "mão única, por haver pouco espaço institucional para a manifestação das famílias".

Mesmo quando a instituição escolar admite a contribuição positiva do trabalho em parceria com as famílias, ainda ocorre certo "tutelamento", no qual a escola tem um conjunto de orientações a serem passadas aos pais/responsáveis como a melhor forma destes participarem da vida escolar de seus filhos (Almeida, 2014). Daí a necessidade do compartilhamento das ações como a melhor opção se há o desejo da construção de um caminho profícuo.

Ribeiro e Andrade (2006, p. 388), em sua pesquisa sobre a relação família e escola, identificaram que na instituição pesquisada por eles havia uma aliança com a comunidade e com movimentos de reinvin- 
dicação junto ao poder público, fato que culminou na expansão de materiais fornecidos e na construção de uma escola para as séries iniciais do ensino fundamental. Contudo, mesmo assim, os autores localizaram nos documentos institucionais e no Projeto Político-Pedagógico (PPP) "prescrições quanto aos deveres dos pais" e a presença do "discurso de famílias deficitárias, em que a ênfase é dada no que os pais não fazem”.

Assim, de modo geral, as pesquisas apontam para pouco espaço de participação ativa e escuta das famílias, sobretudo quanto aos aspectos organizacionais e pedagógicos da instituição.

\begin{abstract}
À família são impostos limites para entrar em questões próprias da escola, como no campo pedagógico. Mas o mesmo parece não acontecer com a escola em relação à sua entrada na família, pois aquela acredita estar autorizada a penetrar nos problemas domésticos e a lidar com eles, além de se considerar apta a estabelecer os parâmetros para a participação e o envolvimento da família (Oliveira; Marinho-Araujo, 2010, p. 104).
\end{abstract}

Nesse sentido, arrisca-se afirmar que há um “modelo" de família idealizado e esperado pela escola, fator determinante na forma como se concretiza a referida relação. Como afirma Lahire (1997), quando a família não apresenta uma forma de acompanhar a vida escolar dos filhos alinhada ao esperado pela escola, cria-se o "mito da omissão parental", produzido pelos próprios professores ao ignorarem a lógica da configuração da família. Dessa forma, "a partir dos comportamentos e dos desempenhos escolares dos alunos [...]" os docentes deduzem "[...] que os pais não se incomodam com os filhos” (Lahire, 1997, p. 334).

Na mesma direção, Viana (2000) identificou que as práticas das famílias provenientes das classes populares, diferentemente das classes médias, não são específicas e intencionais, ou seja, são feitas sem que se constituam como mobilização escolar stricto sensu. Ao não ocorrer um acompanhamento minucioso das atividades escolares, facilmente identificado pela escola, tais famílias são rotuladas como desinteressadas da vida escolar dos filhos ou, ainda, como afirma Albuquerque (2014, p. 622), a elas são atribuídos adjetivos como "famílias desestruturadas, carentes, problemáticas".

Há pesquisas, contudo, que evidenciam as estratégias alternativas utilizadas pelas famílias das classes populares para acompanhar a escolarização dos filhos, em contrapartida à acusação de que desvalorizam as atividades escolares. Lomonaco e Garrafa (2009, p. 34), por exemplo, ao investigarem as formas de acompanhamento da vida escolar dos filhos realizadas por famílias em situações de vulnerabilidade social, destacam que mesmo as mães analfabetas acreditam na importância do acompanhamento das lições de casa e para isso criam formas próprias de ação “[...] como conferir a data no caderno ou ver o quanto ele está preenchido".

Assim, a dissonância entre a percepção da escola sobre a ação da família e a realidade diverge não apenas em relação ao acompanha- 
mento das tarefas escolares como, também, acerca da forma como deve ocorrer a participação da família na escola (Almeida; Betini, 2015).

Contudo, mesmo rotuladas como desinteressadas do processo de escolarização dos filhos, muitas famílias demonstram que gostariam de contar com maior espaço para participar. Como elucida Magalhães (2004, p. 413):

\begin{abstract}
Entre as famílias entrevistadas encontramos aquelas que pensavam que sua relação com a escola era boa e não precisava ser modificada ou apenas era necessário ter reuniões mais frequentes. Entretanto, encontramos várias que gostariam que a relação fosse diferente, gostariam de ter uma relação mais "amistosa", mais participativa, gostariam de conhecer mais a escola e sobre a escola, sobre as mudanças (entendê-las), gostariam de serem envolvidas em atividades e /ou projetos na escola.
\end{abstract}

Para que haja uma "relação mais amistosa e mais participativa", parece ser necessário a construção de uma cumplicidade entre família-escola em uma perspectiva ampla, que ultrapasse o simples acompanhamento de deveres escolares ou a presença em reuniões bimestrais. Como destaca Magalhães (2004, p. 412) "[...] a escola precisaria querer que as famílias de seus alunos participassem da escola, precisaria acreditar nelas e em seu potencial enquanto participantes ativas e não meras receptoras de serviços e normas a serem seguidas".

Neste sentido, estreitar a relação com as famílias poderia contribuir para que as escolas tivessem "maiores informações a respeito de quem são os alunos, suas famílias, sua cultura, sua vida cotidiana" (Reali; Trancredi, 2005, p. 241), bem como favoreceria a presença da voz das famílias na construção do Projeto Político-Pedagógico de uma forma alternativa, propositiva e emancipatória, a partir da realidade local.

Considerar o que os pais/responsáveis têm a declarar permite conhecer a visão do lugar ocupado pela escola em suas vidas e, ainda, observar como os diferentes grupos de pais/responsáveis percebem e demandam esta instituição em dependência de sua posição social (Barbosa; Sant'Anna, 2010). Chamá-los ao diálogo possibilita, também, identificar os grupos que muitas vezes são considerados, equivocadamente, como despreocupados e pouco valorosos da escola (Pinto; Garcia; Letichevsky, 2006).

Por este viés, parece primordial trazer à tona o que pais/responsáveis declaram quando são chamados à fala, de forma a ampliar-se tanto o conhecimento que se tem desse grupo, quanto sua possibilidade real de inserção no cotidiano escolar e no processo de escolarização de seus filhos.

Para tanto, objetiva-se neste trabalho apresentar a visão das famílias acerca da escola e de sua contribuição para a comunidade, de forma a adentrarmos ao que tais atores dizem quando chamados à fala.

Os achados aqui analisados são fruto da pesquisa desenvolvida pelo eixo investigativo Escola, Família e Comunidade, inserido na pes- 
quisa financiada pelo Observatório da Educação - CAPES Avaliação Institucional na Educação Fundamental: potencializando o uso de dados de avaliações externas pelos profissionais da escola (2013).

O objetivo do referido eixo de pesquisa foi conhecer o entorno da escola, em especial a comunidade e a família que nele se inserem, entendendo-o como fator primordial para a compreensão de muitos dos fenômenos que ocorrem no interior da instituição escolar.

Utilizando-se da perspectiva qualitativa de pesquisa, no projeto optou-se pela análise de escolas localizadas em diferentes regiões da cidade de Campinas-SP, a partir de dois movimentos investigativos: 1) realização de entrevista com membros da gestão e a observação das escolas orientada por um roteiro, considerando aspectos como infraestrutura, limpeza, recursos humanos e o relacionamento com a comunidade escolar e o seu entorno; 2) aplicação de questionários para todos os segmentos das escolas (gestão, professores, funcionários, alunos e pais/responsáveis).

Em decorrência das evidências apontadas por pesquisas da área que indicam uma estreita relação entre as condições refletidas no Nível Socioeconômico (NSE), a trajetória educacional e rendimento escolar dos estudantes (Coleman, 1966; Travitzki, 2013; Dalben, 2014, dentre outros), o critério utilizado para a eleição das escolas participantes da pesquisa foi o $\mathrm{NSE}^{1}$ medido no Projeto GERES ${ }^{2}$. Nele, foram compostas amostras representativas das diferentes redes de ensino do município ${ }^{3}$, sendo nossa pesquisa vinculada à rede municipal cuja amostra contou com 20 das 39 escolas da rede ${ }^{4}$. A partir desse critério e objetivando a diversidade na análise, a amostra final foi composta considerando o princípio do contraste, elegendo-se os dois estabelecimentos escolares com maior NSE (E1 e E2) e os dois com menor NSE (E3 e E4), em relação à média da rede, totalizando quatro escolas pesquisadas, cujas características gerais de funcionamento estão apresentadas na tabela a seguir ${ }^{5}$ : 
Tabela 1 - Características gerais das escolas selecionadas

\begin{tabular}{|c|c|c|c|c|}
\hline $\begin{array}{l}\text { : } \\
\text { 台 }\end{array}$ & $\stackrel{\stackrel{2}{N}}{0}$ & $\stackrel{m}{0}$ & $\begin{array}{l}\ddot{n} \\
\dot{i}\end{array}$ & $\begin{array}{l}\hat{n} \\
\text { ô } \\
i\end{array}$ \\
\hline 䒕。 & 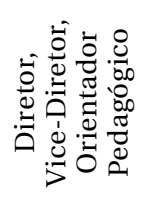 & 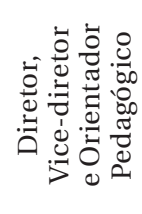 & 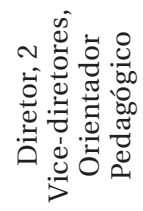 & 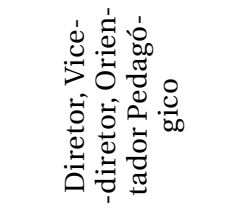 \\
\hline 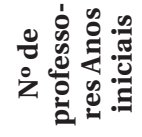 & $\Xi$ & $\sigma$ & $\stackrel{\infty}{\sim}$ & ిల \\
\hline 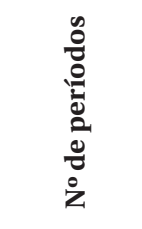 & 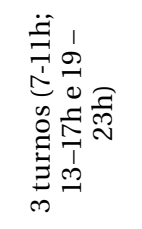 & 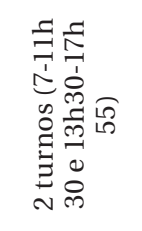 & 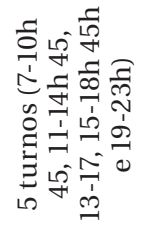 & 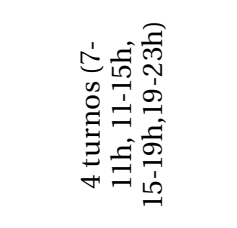 \\
\hline 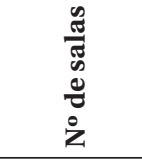 & 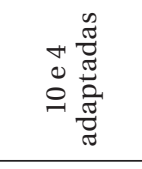 & 0 & 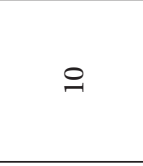 & 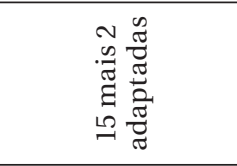 \\
\hline 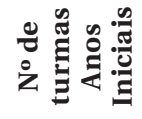 & $\stackrel{\sim}{\sim}$ & 10 & $\stackrel{\varrho}{\prime}$ & $\simeq$ \\
\hline & 营 & 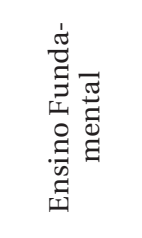 & 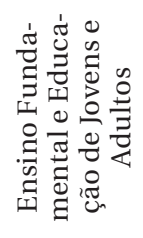 & 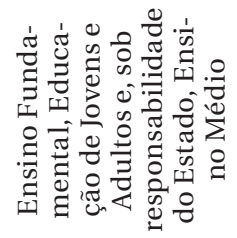 \\
\hline \multirow[t]{2}{*}{ 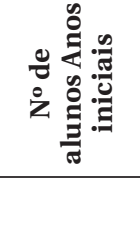 } & 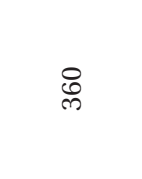 & $\stackrel{m}{\rightarrow}$ & : & ¿ \\
\hline & 포 & 포 & జ్1 & 嵌 \\
\hline
\end{tabular}

Fonte: Elaboração dos autores com base em Betini; Almeida (2010).

Tomando como universo as turmas de quartos e quintos anos das escolas selecionadas, foram enviados questionários a todos os pais/responsáveis pelos estudantes de tais turmas existentes nas escolas participantes da pesquisa. Ainda que o retorno dos questionários, em núme- 
ros relativos, tenha sido alto nas instituições investigadas, houve certa variação entre elas, como pode ser observado na tabela abaixo.

Tabela 2 - Quantidade de questionários enviados e respondidos pelas famílias

\begin{tabular}{|c|c|c|c|}
\cline { 2 - 4 } \multicolumn{1}{c|}{} & $\begin{array}{c}\text { Quantidade média de } \\
\text { questionários envia- } \\
\text { dos por escola }\end{array}$ & $\begin{array}{c}\text { Quantidade absoluta } \\
\text { de questionários res- } \\
\text { pondidos por escola }\end{array}$ & $\begin{array}{c}\text { Quantidade relativa } \\
\text { (\%) de questionários } \\
\text { respondidos por es- } \\
\text { cola }\end{array}$ \\
\hline E1 & 120 & 85 & 70,8 \\
\hline E2 & 60 & 47 & 78,3 \\
\hline E3 & 210 & 154 & 73,3 \\
\hline E4 & 245 & 178 & 72,6 \\
\hline
\end{tabular}

Fonte: Elaboração dos autores.

O questionário aplicado às famílias teve 13 questões (10 fechadas e 3 abertas). As questões abertas possibilitaram que os familiares tecessem considerações acerca da contribuição da escola na comunidade e desta na escola, permitindo ainda que os respondentes falassem sobre outras temáticas que achassem importante destacar, fato que justifica a escolha por analisá-las, já que demonstram a visão desses sujeitos acerca do que julgaram relevante mencionar, ou seja, as questões latentes para estes sujeitos.

As questões abertas propostas às famílias foram:

- Essa escola contribui na vida do bairro? Como?

- Este bairro contribui na vida da escola? Como?

- Se você deseja fazer algum outro comentário, utilize o espaço abaixo.

Vale destacar que embora as questões focassem a contribuição da escola no bairro e vice-versa, as respostas obtidas, ultrapassaram o que foi solicitado e, a partir delas, os pais/responsáveis relataram e, a seu modo, definiram aspectos que influenciam na qualidade institucional, bem como elencaram fatores vinculados à escolarização de seus filhos, versando sobre como ocorre a relação com a instituição escolar.

Dessa forma, as respostas obtidas a partir das questões apresentadas, demonstraram uma grande riqueza de apontamentos assim como a expressão de diferentes significados e valorações acerca da instituição escolar, as quais não se limitaram a averiguações sobre sua função e funcionamento, abrangendo, em muitos momentos, um tom de demanda sobre o que a instituição escolar deveria atender ou oferecer, objeto de nossa análise na próxima seção, em que apresentaremos a voz das famílias pesquisadas.

\section{A Escola Vista De Fora: o que é destacado acerca da escola quando chamamos as famílias a opinarem?}

De acordo com Castro e Regattieri (2009, p. 44) e como já vínhamos discutindo anteriormente, a escola, ao colocar-se enquanto "centro" na relação estabelecida com os pais/responsáveis, desconsidera a 
necessária observação dos contextos familiares e posiciona-se como capaz de prescrever modelos a serem assumidos pelas famílias. Nas palavras dos autores:

Segundo várias pesquisas, as escolas frequentemente representam as famílias como uma extensão de si mesmas, sem perceber as diferenças de lógica de um espaço a outro. Esse traço, de colocar a lógica da instituição escolar no centro do diálogo, é chamado escolacentrismo e costuma impedir que os agentes escolares escutem e compreendam o ponto de vista das famílias.

Ao posicionar-se dessa forma, atribuindo a necessidade de "tutela" aos comportamentos familiares, a escola silencia a diversidade de temas trazidos pelos pais/responsáveis, os quais permitem observar a percepção das famílias acerca da instituição, com possibilidade de beneficiar, a partir do ponto de vista vindo de fora, o trabalho específico da escola.

O chamamento às famílias para opinarem acerca da escola e sobre a relação desta com a comunidade atendida mostra a multiplicidade de temáticas trazidas por tais sujeitos quando se reportam à instituição escolar que atende seus filhos.

A visão dos pais/responsáveis, expressa nos dados, trouxe muitos aspectos referentes ao fator de apreciação da escola frequentada pelos filhos, quanto outros voltados a percepção das atividades desenvolvidas pela instituição e suas potencialidades ou fragilidades em relação ao que julgam ser ações importantes a serem realizadas.

Tendo em vista a diversidade dos temas abordados, as declarações das famílias foram agrupadas pelo conteúdo referido e organizadas em seis diferentes temas de análise, a saber: 1) Qualidade do Ensino; 2) Relacionamento escola-comunidade; 3) Organização escolar; 4) Razões da apreciação da escola; 5) Atividades extraturno; 6) Segurança.

Para fins analíticos, a partir da leitura dos questionários recebidos, foram consideradas as questões abertas respondidas e calculada a frequência em que cada temática foi levantada pelos respondentes em cada escola, como pode ser observado na tabela 3. Analisar tal frequência auxilia na observação dos aspectos citados pelas famílias de cada escola, elucidando o que é mais marcante para elas quando podem falar sobre a instituição escolar frequentada por seus filhos.

Tabela 3 - Frequência de resposta por temática nas escolas pesquisadas $^{7}$

\begin{tabular}{|l|c|c|c|c|}
\cline { 2 - 4 } \multicolumn{1}{c|}{} & E1 & E2 & E3 & E4 \\
\hline Qualidade do ensino & $31,4 \%$ & $37,2 \%$ & $26,3 \%$ & $41,3 \%$ \\
\hline Relacionamento escola-comunidade & $18 \%$ & $28,6 \%$ & $8,3 \%$ & $5,6 \%$ \\
\hline Organização escolar & $3 \%$ & $11,5 \%$ & $1,5 \%$ & $4,2 \%$ \\
\hline Razões de apreciação da escola & $12 \%$ & $17,2 \%$ & $16 \%$ & $26 \%$ \\
\hline Atividades extraturno & $4,5 \%$ & $11,5 \%$ & $15 \%$ & $12 \%$ \\
\hline Segurança & $6 \%$ & $0 \%$ & $4,5 \%$ & $9 \%$ \\
\hline
\end{tabular}

Fonte: Elaboração dos autores. 
Ao analisar os dados, chama a atenção a presença de aspectos apontados por muitos respondentes voltados a uma percepção da qualidade do ensino ofertado, bem como de aspectos relacionados à demanda e a valoração quanto ao que estes estabelecimentos promovem ou deveriam promover.

\section{Qualidade do Ensino}

As respostas que, de alguma forma, fazem referência especificamente à qualidade do ensino evidenciam que aspectos relacionados ao ensino-aprendizagem são valorizados pelos pais/responsáveis, sendo, esta temática, a que apresentou maior frequência de respostas nas quatro instituiçõos pesquisadas, embora não abordadas a partir de uma mesma perspectiva.

No que tange as declarações associadas ao ensino ofertado pela instituição, agrupadas na temática Qualidade do Ensino, observa-se tanto relatos positivos relacionados ao ensino de forma geral, e a alfabetização das crianças de forma específica, quanto depoimentos negativos, sinalizando descontentamento com o trabalho da instituição neste aspecto.

Entre os aspectos positivos são indicados, dentre outros, a aprendizagem observada pelos pais/responsáveis no processo de escolarização dos alunos e a tradição e fama da escola, as quais teriam relação direta com os processos de ensino-aprendizagem e organização da escola. Já entre os aspectos negativos, são citados a não aprendizagem por parte dos estudantes, especialmente a não alfabetização de alunos já nos quartos ou quintos anos, e a falta de professores e desorganização escolar que acarretam descontinuidade do trabalho em sala de aula, gerando ônus à aprendizagem.

Interessante observar, como exemplificado pelas declarações a seguir, que o aspecto negativo e depoimentos direcionados à falta constante de professores aparecem com maior frequência na escola E4, enquanto o ensino de boa qualidade e a tradição institucional, decorrente de tal característica, são mais enfatizados na escola E1.

A escola pra mim sempre foi boa, a única reclamação que tenho é que meus filhos não sabem nada e não sabem ler nem escrever nada. Gostaria de saber porque eles passam as crianças de série se não sabem nada. Ele [o filho] reclama que a professora não passa lição, mas ele não sabe fazer (E4, Pai/Responsável 3) ${ }^{8}$.

[...] escola já antiga, conhecida e reconhecida por muitos moradores, sempre foi reconhecida como uma escola de boa qualidade (E1, Pai/Responsável 26).

Ainda acerca da qualidade do ensino, nota-se que embora a maioria das colocações relacione-se ao aspecto instrucional, há respostas que fazem referência à escola como relevante na formação mais ampla dos estudantes, especialmente quanto à construção de valores e relacionamentos sociais, como exemplificado a seguir: 
[a escola contribui] Tentando ensinar as pessoas a viverem sociavelmente (E1, Pai/Responsável 1).

[...] ajuda na formação de bons cidadãos para o futuro, já ajuda bastante. (E2, Pai/Responsável 4).

[a escola contribui] formando um bom cidadão (E3, Pai/Responsável 26).

Vale ressaltar que se encontrou a temática qualidade do ensino associada também à possibilidade de um futuro melhor e de inserção no mercado de trabalho, aspecto denominado na literatura como interesse instrumental.

Barbosa e Sant'Anna (2010), apoiados em trabalhos anteriores, afirmam que entre os mais pobres é a visão da valorização da educação como um instrumento para melhoria de vida que impera, enquanto em classes mais favorecidas há uma significação simbólica da frequência à escola, havendo relação com realizações pessoais e projetos de vida a longo prazo.

Na mesma direção, Pinto, Garcia e Letichevsky (2006), em pesquisa realizada acerca da qualidade da educação na perspectiva dos pais, ressaltam que as famílias em situações vulneráveis depositam em seus filhos a esperança de, por meio do estudo, melhorarem as condições de vida.

Corroborando com o debate, Zago (2000) e Lomonaco e Garrafa (2009) ampliam a análise ao afirmarem que para as famílias das classes populares, além de possibilitar a inserção no mercado de trabalho, a escola também, e por isso, simboliza a possibilidade de romper com as condições de pobreza.

Para elas, a escola é mais do que uma possibilidade de aprender, é a única saída para se 'ter uma vida melhor'. O estudo, para todas elas, confere um lugar social, dá um nome e uma identidade. Essa identidade traz a história do sujeito (e de seus antepassados) e o lança para o futuro, como uma nova possibilidade de ser um igual (aos seus), mas também um novo (Lomonaco, Garrafa, 2009, p. 32).

Chama a atenção, por confirmar as indicações da literatura, que a maior frequência de falas ligadas ao interesse instrumental, como exemplificado no trecho destacado a seguir, tenha sido obtida nas escolas E3 e E4 que são aquelas localizadas em regiões mais empobrecidas da cidade, sendo as escolas de menor NSE de nossa amostra.

Porque as crianças aprendem a ler e escrever para ter um futuro melhor e para estar bem preparadas no mercado, para conseguir um bom emprego (E4, Pai/Responsável 24).

Um destaque importante a fazer é que embora famílias de diversos níveis socioeconômicos demonstrem interesse quanto à qualidade do ensino ofertado pela escola, ao serem analisadas as falas à luz de pesquisas da área, especialmente aquelas da sociologia da educação (Dayrell et al., 2012), pode-se observar que a diferença está associada, 
possivelmente, aos modos de aproximação entre os diferentes grupos sociais e a instituição. Segundo Thin (2006a), alguns com modelos de socialização mais próximos aos assumidos pela escola e outros menos.

\section{Relacionamento Escola-Comunidade}

Na temática Relacionamento escola-comunidade o relacionamento entre família e escola foi mais destacado e valorizado pelos pais/responsáveis com maior nível socioeconômico, o que se poderia relacionar à afirmação de Zago (2000, p. 10) quando se refere à "interdependência entre condições sociais das famílias e as formas de relação com a escola”.

Nos dados analisados, o bom relacionamento da escola com a comunidade é fortemente destacado pelas famílias da instituição E1, de maior NSE, as quais, possivelmente, apresentam uma cultura familiar mais próxima ao exigido pela escola, se sentem mais próximas desta instituição e de seus padrões. Há, nos depoimentos da escola E1, o enaltecimento da escola como propulsora dos vínculos entre os moradores do bairro, como destacado pelo Pai/Responsável 1. Vale destacar que nas escolas de menor NSE tal aspecto se volta à oferta de atividades e oficinas de caráter compensatório, considerando que a região em que a escola se encontra não oferece alternativas de lazer ou atividades diversificadas.

[a escola] Promove atividades que promovem a integração entre os moradores (E1, Pai/Responsável 1).

De modo geral, ao descreverem o relacionamento entre escola e comunidade as famílias citam a participação nos eventos locais e nas reuniões promovidas pela escola e a disponibilidade da instituição em possibilitar o uso do espaço escolar para demais atividades do bairro que não necessariamente sejam a ela vinculadas.

Como destacam Ribeiro e Andrade (2006), a relação família e escola e a participação da primeira na segunda deve ser apurada. Os referidos autores relatam, em sua pesquisa, que as mães que descreveram a relação com a escola de forma amistosa, sentiam-se incluídas nas atividades escolares, pois lhes eram permitidas a participação em eventos e nas campanhas para arrecadar dinheiro, contudo, a relação era definida pela submissão da família diante da escola, a partir do que esta definia. Entretanto, eram tais mães que possuíam "algum acesso aos espaços decisórios da instituição (se é que eles realmente ocorrem), como Conselho de Pais e Associação de Pais e Mestres" (Ribeiro; Andrade, 2006, p. 389).

A participação das famílias no cotidiano escolar deve ser analisada sob várias dimensões a fim de que se tenha clareza sobre qual participação e qual relação se estabelece. Entende-se, pois, que a participação e a relação família-escola podem ocorrer em diferentes níveis, desde o "tutelamento" da instituição desconsiderando, se necessário, a lógica familiar, passando por uma participação camuflada e um relaciona- 
mento de submissão, até a participação efetiva e cúmplice das famílias com voz ativa e possibilidades deliberativas nas decisões escolares, inclusive em seu Projeto Político-Pedagógico. Tais níveis, entretanto, não são sequenciais e ainda outros devem existir. O que vale destacar é que em cada contexto e, independentemente do NSE, as famílias são parte integrante da instituição escolar, já que seus filhos são os alunos destas escolas e, consequentemente, o sujeito comum entre estas instituições.

O que ocorre muitas vezes é que "as famílias das crianças não são compreendidas na complexidade das relações sociais, culturais, econômicas e de afeto que as constituem" (Albuquerque, 2014, p. 622) e, ao não serem entendidas em sua lógica organizacional, são interpretadas e rotuladas como negligentes e displicentes nas questões educacionais que abarcam seus filhos.

Os dados da presente pesquisa permitem a identificação de menções à importância dada por famílias de menor NSE à participação dos pais/responsáveis no cotidiano escolar, convergindo com o diagnosticado por outras pesquisas (Lahire, 1997; Lomonaco; Garrafa, 2009; Albuquerque, 2014, entre outros). As falas de pais/responsáveis da escola E4 mencionam que participar da vida escolar dos filhos pode contribuir com a escola e também para a autoestima da criança, como exemplificamos no trecho a seguir:

Que a escola possa proporcionar para os pais e filhos um encontro pelo menos uma vez ao mês para que elas [crianças] vejam que são importantes para os pais. Se sintam seguras e melhorem na área de educação entre colegas de classe e respeitem uns aos outros, que é o mais importante. Para que os professores possam trabalhar sem estresse. (E4, Pai/ Responsável 70).

Albuquerque (2014, p. 620, grifos do autor) identificou em seu estudo o desejo das famílias em dialogar e participar de forma efetiva da instituição escolar, demonstrando preocupação com a educação escolar dos filhos e, sobretudo, reivindicando um "olhar atento em relação à vivência das crianças na escola”.

Percebe-se, pelos dados analisados, certa submissão das famílias ao que é estabelecido pela escola, especialmente entre àquelas de menor NSE as quais, como evidenciado por Almeida (2014), pela própria posição social, têm menor identificação com o modelo escolar, se distanciando do que a escola prescreve como o ideal. Esse aspecto conflita com o defendido por estudiosos da área quando indicam a necessidade de uma relação horizontal, cuja intenção não seja de dominação desta sobre aquela. As prescrições dadas pela escola além de inferiorizar as famílias, já que muitas se sentem envergonhadas por não conseguirem acompanhar as tarefas dos filhos (Ribeiro; Andrade, 2006), não contribuem para a formação e o desenvolvimento das crianças e podem levar à exclusão dos menos favorecidos do sistema escolar.

Alguns entrevistados mostraram se esforçar muito para cumprir as regras, mas isto nem sempre era possível, o que pareceu gerar sentimento de vergonha. Diante desta

660 Educação \& Realidade, Porto Alegre, v. 42, n. 2, p. 649-671, abr./jun. 2017. 
situação, eles têm atitudes de desistência, agressividade e afastamento. Portanto, este seria um dos sérios impasses que ocorrem cotidianamente e que vão criando o que se chamaria de um mecanismo sutil de exclusão [...] (Ribeiro; Andrade, 2006, p. 391).

Curiosamente, na escola E3, ainda que se encontre falas que sinalizem para uma abertura da escola à comunidade e uma boa relação com as famílias, há também, em quantia proporcional, famílias que solicitam maiores possibilidades de participação no cotidiano escolar, fato que reforça a consideração quanto à necessária análise cuidadosa, a partir de várias perspectivas, quanto às formas de participação e de relacionamento que se estabelecem entre família e escola. Como evidenciado no trecho a seguir, por vezes a família deseja uma aproximação maior com a instituição, se sentindo capaz de intervir não só nas questões de aprendizagem e comportamento de seus filhos, como de decisões escolares, exemplificadas na fala pela destinação de recursos.

Sugiro que a escola venha a contribuir mais, na forma de atrair [e] permitir a participação de pais e comunidade para com os assuntos da instituição escolar, quer seja na forma de sanarmos problemas e dificuldades de aprendizado, comportamentos dos alunos, [como] quanto a aplicação dos recursos financeiros da escola (E3, Pai/Responsável 2).

Todavia, vale apontar que tal reivindicação pode estar ligada simplesmente à própria ação de participar, na qual aqueles que vivenciam a possibilidade de participação sentem maior necessidade de exercê-la, avaliando como insuficientes as já consolidadas. Assim, a prática de participar conduziria ao desejo de sua maior efetivação.

Outro aspecto presente nas declarações de algumas famílias é a menção à organização interna das escolas, a qual se nomeou como Organização Escolar.

\section{Organização Escolar}

Embora o número de declarações acerca da temática Organização Escolar não seja alto, suas observações são importantes por fazerem menções ao estilo de gestão ou à forma como a escola está organizada para atender às crianças, especialmente relativas à limpeza e à refeição oferecida, como exemplificado nos trechos a seguir.

Gostaria que a escola tivesse uma limpeza semanal ou quinzenal, pois apresenta um abandono na área ambiental da escola e nos brinquedos da própria escola (E1, Pai/Responsável 47).

Na minha opinião a escola deveria mudar algumas coisas, algumas regras que antigamente tinham [e] que hoje deveria [voltar a] ter, quem sabe os alunos teriam mais respeito pelos professores e pela própria escola (E3, Pai/Responsável 75).

É uma escola cuja diretoria é muito exigente, isto segura a qualidade do ensino (E2, Pai/Responsável 11). 
A organização institucional, enquanto uma das funções relacionadas à gestão escolar, foi identificada na pesquisa de Pinto, Garcia e Letichevsky (2006) como fator associado à qualidade do ensino na escola, coincidente com a fala do pai/responsável 11 da escola E2, destacada anteriormente, cuja instituição de pertencimento houve o maior número de menções à temática.

Ainda nesta temática, os respondentes da escola E4 mencionam recorrentemente a indicação da necessidade de melhoria na organização da instituição e o problema do baixo número de horas que as crianças ficam na escola.

Tanto na escola E4, quanto na escola E3, como exemplificado nos trechos a seguir, a menção à inadequação do tempo de permanências dos alunos na instituição escolar é citada, indicando aparente relação com o fato de ambas se organizarem em períodos intermediários e, em decorrência disso, terem apenas quatro horas de aula ao dia.

O horário de ensino dessa escola é muito pouco. Por causa disso, muitos alunos não rendem na escola (E3, Pai/Responsável 42).

A escola é regular porque falta muitos itens para ser uma escola boa. [...] fazer quadras, aproveitar o espaço com coisas criativas. Melhorar 100\% a organização porque é péssimo fazer parquinho, melhorar a biblioteca etc. (E4, Pai/Responsável 66).

Percebe-se, também, que é recorrente a declaração entre pais/ responsáveis de que a escola em que seu filho está matriculado é boa simplesmente porque é próxima de sua residência, em um bairro bom, de fácil acesso ou por ser positiva para o desenvolvimento local, já que com ela outras melhorias de infraestrutura urbana foram trazidas à localidade. Apontamentos que se convencionou agrupar no que foi chamado de Razões da apreciação da escola.

\section{Razões da Apreciação da Escola}

Ainda que a temática Razões de apreciação da escola esteja presente nas diferentes instituições faz-se necessário evidenciar que tal aspecto foi mais destacado pelos respondentes da escola E4. Parte das declarações ressalta a presença da escola na localidade como fator estimulador para que melhorias de infraestrutura sejam realizadas no bairro, como declara o pai/responsável 6 quando relaciona a existência da escola com as chances da prefeitura investir em infraestrutura. Importante destacar que as condições de infraestrutura do bairro onde a escola E4 se localiza são as menos positivas, sem rede de tratamento e afastamento de esgoto, ruas não asfaltadas, rede de saúde em imóveis improvisados, dentre outros.

Ainda neste aspecto, e como evidenciado na declaração a seguir, há respostas que sinalizam a importância da proximidade entre moradia e escola como fator que dispensa a necessidade de gasto com transporte e/ou a necessidade de deslocamento para um bairro distante.

662 Educação \& Realidade, Porto Alegre, v. 42, n. 2, p. 649-671, abr./jun. 2017. 
[...] é uma escola perto que não [exige a] necessidade de ônibus para chegar até ela. Porque não são todas as pessoas que têm condições de estar pagando ônibus para as crianças (E4, Pai/Responsável 82).

Destaque oposto foi dado nas respostas das famílias da escola E1, localizada no bairro de melhor infraestrutura urbana da amostra, as quais ressaltam a localização da instituição escolar como ponto positivo, como exemplificado na declaração do pai/responsável 12:

[é uma escola boa por estar em] um bairro próximo do centro da cidade e de várias linhas de ônibus circular (E1, Pai/Responsável 12).

Outra temática construída a partir das declarações das famílias foi Atividades Extraturno, em que é possível observar a valorização, por parte das famílias, das atividades extracurriculares oportunizadas pelas escolas.

\section{Atividades Extraturno}

As Atividades Extraturno foram explicitadas em diferentes falas, todavia a escola que mais cita essas atividades é a E3, exemplificado nos trechos destacados a seguir. Isto está circunstanciado pela realidade vivenciada na instituição, cuja oferta de projetos aos finais de semana para as crianças e comunidade é vista como importante, principalmente porque atividades culturais, de acesso a computadores ou esportivas são quase inexistentes na região em que a escola se localiza.

[...] promove lazer e esportes para todos os moradores do bairro, com isso ajuda a tirar adolescentes da rua (E3, Pai/Responsável 9).

[...] hoje a escola tem promovido um projeto como aulas de danças, teatro, capoeira, expressão corporal, aulas de reforço de matemática e português... Isso é uma maneira de incentivar crianças à arte e melhorar o rendimento. E o projeto não é só para alunos, também estende-se às crianças do bairro (E3, Pai/Responsável 27).

Sem a mesma oferta de atividades que a escola E3, chama a atenção a declaração do Pai/Responsável 12 da escola E4, corroborada por outras, que menciona a necessidade de a escola se abrir para outras atividades que não somente as aulas, estando disponível aos alunos, pais e demais moradores do bairro. Solicitação, no entanto, limitada pela realidade da própria escola que, como já evidenciado na Tabela 1 e exemplificado pela declaração do Pai/Responsável 89 a seguir, não pode oferecer atividades no contraturno por sua estrutura física e organizacional a qual, dentre outros limitantes, é organizada com o período intermediário, contando com quatro turnos e, portanto, ao contrário do que realiza a escola E3, não disponibiliza atividades aos finais de semana.

Gostaria que tivesse mais atividades na escola, mas o período impede. Gostaria que tivesse aulas de capoeira, ginástica, aula de circo e teatro, natação... Enfim, atividades desse tipo, pois só assim desde cedo nossos filhos tomariam gosto por uma atividade (E4, Pai/Responsável 89). 
Um aspecto importante a se destacar, ponto de análise em trabalho anterior (Malavasi et al., 2012), é que em vários depoimentos a menção às atividades extracurriculares está ligada a uma apreciação dessa oferta como oportunizadora de retirada das crianças da rua. Exemplo disso é a própria escola E4 em que os pais/responsáveis declaram a importância das atividades na escola como essenciais para que as crianças não fiquem nas ruas, o que, inclusive, um dos pais reivindica nomeando como escola em período integral.

Tal perspectiva da questão da oferta de atividades no turno oposto ao horário regular de aulas dos alunos, no entanto, foi ponderada por Arroyo (2010). O autor analisa a necessidade do cuidado com projetos de extraturno pois, muitos deles, objetivam simplesmente o afastamento das crianças e jovens das ruas sem considerar, mais fortemente, as questões de desigualdade social e os objetivos educacionais envolvidos. Perspectiva que deve influenciar principalmente os objetivos pedagógicos da escola, porque ainda que as famílias mencionem a necessidade de tirar seus filhos da rua, ao falarem também da expectativa de que eles aprendam na escola, como discutido anteriormente, estão reivindicando que as atividades escolares visem a aprendizagem, embora não tenham a clareza das dimensões pedagógicas para se expressarem.

Um aspecto interessante e que pode estar associado a esta questão é a percepção de violência no bairro por parte das famílias. Situações de violência vivenciadas pelos moradores do bairro também são citadas nas respostas dadas ao questionário, as quais podem justificar a preocupação das famílias em manter as crianças ocupadas, afastando-as, portanto, dos caminhos oferecidos pela rua. Zago (2000) auxilia esta análise quando afirma que os pais, sujeitos de sua pesquisa, também viam a escola tanto como espaço de instrução, quanto de socialização e consequente afastamento da violência e das drogas.

Nesta perspectiva, e compondo com ela, as famílias reforçam tal questão, com considerações que convencionamos agrupar na temática Segurança.

\section{Segurança}

Nos relatos classificados na temática Segurança, as famílias fazem menção à presença ou ausência de segurança no interior e no entorno da instituição. Como destacado a seguir, nas escolas E3 e E4, as falas sinalizam para a falta de segurança na escola e no bairro, havendo, inclusive, pedidos de ronda escolar. Dentre outras percepções importantes, existem aquelas que colocam os profissionais como temerosos de trabalhar na escola já que o bairro não é bem visto devido à falta de segurança.

Eu acho que deveria ter guarda municipal todos os dias na porta e dentro da escola para ver se os alunos e meninos de fora respeitavam a todos. (E3, Pai/Responsável 1). 
[...] a falta de segurança e o pânico [é o] que tira a paz e que derrota a qualidade de ensino e torna as coisas muito difíceis para quem quer aprender (E4, Pai/Responsável 62).

[...] muitos professores deixam de vir dar aula nesta escola porque têm medo de entrar neste bairro (E4, Pai/Responsável 24).

Diferentemente da E3 e da E4, contudo, a escola E1, com melhores condições de infraestrutura, cita como potencialidade da instituição, destacado na declaração do pai/responsável 35, a presença de um guarda/vigilante que não deixa as crianças saírem sozinhas. Aspecto que confere maior confiança das famílias no cuidado da escola para com seus filhos.

Estamos satisfeito com a qualidade da escola em relação ao ensino e a segurança das crianças, "ninguém sai do portão sem o pai ou responsável", isso nos dá tranquilidade para deixarmos os nossos filhos na escola (E1, Pai/Responsável 35).

Interessante notar que a escola $\mathrm{E} 2$ não faz nenhuma menção à questão da segurança, o que pode indicar certa tranquilidade acerca da temática entre as famílias frequentadoras da escola. Observação que unida à percepção positiva da segurança pelos pais/responsáveis da escola E1 pode sinalizar certa relação desta temática com as condições de vida do bairro atendido pela escola, já que nas escolas de maior NSE (E1 e E2) a segurança não é a maior preocupação e nas escolas de menor NSE (E3 e E4) ela é vista como um problema a ser enfrentado.

\section{Considerações Finais}

Objetivando apresentar a visão das famílias sobre a escola e a contribuição desta para a comunidade, o presente artigo trouxe à tona a visão de pais/responsáveis de quatro escolas municipais acerca da escola frequentada por seu(s) filho(s).

Com o intuito de conhecer o que tais atores têm a dizer quando chamados à fala, agrupou-se os núcleos de conteúdo trazidos em suas declarações em seis temáticas analíticas, as quais permitiram não apenas observar seus apontamentos, como também diferenças aparentemente ligadas à posição social que ocupa o grupo familiar, aqui observadas sob a proxy "nível socioeconômico".

As seis temáticas obtidas a partir das falas analisadas evidenciam que há um conjunto de aspectos observados pelos pais/responsáveis quanto à instituição escolar onde seus filhos estão matriculados. Tais aspectos, se considerados e analisados pela escola, podem, certamente, contribuir para a construção de certa confluência de objetivos e propostas entre a instituição escolar e famílias, com grandes benefícios ao aluno, a partir do planejamento de ações mais específicas e apropriadas, assim como a utilização das perspectivas das famílias como impulsionadora da melhoria do trabalho desenvolvido. Nas palavras de Zago (2012, p. 145), tomando o trabalho de Charlot e Rochex:

Educação \& Realidade, Porto Alegre, v. 42, n. 2, p. 649-671, abr./jun. 2017. 
[...] [Haveria] a necessidade de não se estabelecer julgamento da relação escola-família a partir somente das formas visíveis que reconhecem a escola, mas trabalhar para elucidar a diversidade de processos que dão forma e conteúdo nos diferentes meios sociais e constelações familiares.

Os achados analisados permitem perceber não apenas a visão das famílias a partir do lugar ocupado pela escola em suas vidas, como, também, identificar que, ao serem chamadas ao diálogo, as famílias apontam ações, as quais podem elucidar questões nem sempre claras aos profissionais, complementando o conhecimento da instituição escolar vista por outro ângulo, ou seja, uma visão externa, de fora, que ultrapassa os muros escolares.

Pode-se notar que quando chamadas à fala as famílias têm muito a dizer e que dar voz a elas permite uma melhor compreensão da população atendida, seus anseios, dúvidas, reivindicações e proposições.

Assim, aproximar-se das famílias, em uma posição solidária de escuta e diálogo, em oposição ao "tutelamento" observado por vários estudos, corrobora para a desmistificação da "omissão parental" apontada por Lahire (1997) e, sobretudo, abre a possibilidade de o Projeto Político-Pedagógico da escola ser realmente construído por seus diversos segmentos, inclusive as famílias que há tanto tempo são silenciadas neste processo. Essa posição solidária e de diálogo exige que os profissionais da escola se abram para uma outra lógica, na qual as famílias são chamadas para fazer parte dos tempos e espaços de reflexão e decisão, em um sentido de construção plural da história da escola.

Nesse sentido, a atuação conjunta entre escola e famílias permite, por exemplo, a reivindicação junto ao poder público para melhoria de aspectos que possam favorecer o trabalho escolar, caso das escolas E3 e E4 que com uma estrutura física, organizacional e de equipe mais adequadas poderiam melhorar o atendimento à população com mais horas de aula por turno e a criação, ou expansão, das atividades extraturno.

Dessa forma, escutar as famílias, além de desconstruir a imagem feita por muitos profissionais de que elas não se interessam, não valorizam a escola, suas pautas e agendas, é fundamental para que a escola aceite que as famílias, de fato, podem contribuir para os avanços institucionais.

Nos dados analisados, a formação cognitiva ainda prevalece na fala dos pais/responsáveis, contudo, a análise das famílias ultrapassa o "saber ler e escrever". Elas reconhecem que a escola precisa estabelecer novos vínculos com a comunidade, abrindo suas portas para as diversas vozes, colaborando, conseguinte, para a formação de atitudes e valores emancipatórios. Reconhecem, ainda, as potencialidades da instituição e destacam o trabalho desenvolvido pelos professores, entretanto, conseguem identificar onde as melhorias são necessárias.

Nesse sentido, chama a atenção a clareza de alguns pais/responsáveis em relação ao que a escola oferece ou não a seus filhos, assim 
como o que deveriam oferecer, como maior número de atividades extraturno e a segurança destes quando estão na escola, ansiando, ao mesmo tempo, a instrução e a socialização de seus filhos neste espaço. Nas palavras de Zago (2012, p. 139):

No plano mais imediato, a escola representa para os pais uma necessidade para aquisição dos saberes fundamentais, para a ocupação dos filhos quando as mães trabalham fora, mas é também reconhecida como lugar de socialização e proteção dos filhos do contato com a rua, do mundo das drogas, das más companhias, indicando a inseparabilidade entre instrução e socialização.

A percepção, explicitada pelas famílias de verem a escola como um local onde seus filhos devem estar protegidos, guardados e afastados da rua, também mostra como a preocupação com questões relacionadas a violência são cotidianas para toda população. Supor que filhos oriundos de famílias de menor NSE se preocupam menos com tal fato, ou que o banalizam, não parece correto. Para essas famílias, assim como para as demais, segurança é um dado preocupante e a escola se insere na perspectiva de um lugar seguro para crianças.

Por outro lado, os dados analisados nos levam a observar diferenças importantes entre as escolas pesquisadas, as quais, em vários aspectos, parecem ter relação com as condições de vida das famílias atendidas. Desse modo, como já apontado na literatura, há diferenças entre grupos sociais e sua relação com a escola (Barbosa; Sant'Anna, 2010; Thin, 2006b; Paixão, 2006; Viana, 2000, dentre outros).

Fica evidente, portanto, que os pais/responsáveis têm muito a dizer sobre a escola de seus filhos e, nesse caso, vale questionar: apenas as reuniões bimestrais são suficientes para aproximar as famílias da escola? Quais os momentos existentes e necessários para a acolhida das famílias? Como construir uma relação de cumplicidade entre família e escola? As respostas para tais questões não são simples e universais. Para cada realidade haverá um caminho que leva a necessária cumplicidade entre família-escola. No entanto, para romper com a relação "unilateral” em que os pais/responsáveis são aceitos na instituição conforme esta determina, conferindo-lhes uma participação secundária (Reali, Tancredi, 2005), a instituição escolar pode dar o primeiro passo e, ao estabelecer formas alternativas de contato com as famílias, construir um novo elo envolvendo as duas realidades comuns à criança, ou seja, sua família e sua escola.

Como afirma Albuquerque (2014, p. 624):

[...] acolher as famílias no cotidiano da escola implica numa decisão política e pedagógica que prevê ações e interações vivenciadas no cotidiano, que podem ser pensadas a partir das seguintes questões: qual o local onde as famílias são recebidas na escola? As portas e portões estão sempre abertos? Em quais horários e como são recebidas às famílias no cotidiano da escola? Como são acolhidas suas críticas e sugestões? Quais os mecanismos de 
participação na gestão da escola em que as famílias são incluídas? Quais os tempos e espaços que as professoras encontram no cotidiano para estabelecer um diálogo efetivo com as famílias das crianças?

Conhecer, se apropriar e dialogar com as famílias atendidas parece um caminho ainda pouco percorrido pelas escolas, entretanto promissor na compreensão da realidade vivenciada e, especialmente, aproximador dessas duas importantes partes, as quais trabalhando conjuntamente poderiam melhorar a trajetória de escolarização das crianças e jovens, objetos da ação escolar.

Recebido em 01 de junho de 2015 Aprovado em 09 de dezembro de 2016

\section{Notas}

1 "Do ponto de vista mais operacional, o NSE é tomado como um construto teórico, ou seja, uma variável latente (não diretamente observada) cuja medida é feita ao agregar informações sobre: a educação, a ocupação e a riqueza ou rendimento dos indivíduos" (Alves e Soares, 2009).

2 O Projeto GERES foi um estudo longitudinal que mediu o desempenho de estudantes nos anos iniciais do ensino fundamental, coletando dados de contexto das escolas para cruzamento e análise destes dados relacionados ao desempenho. Ver Franco, Brooke e Alves (2008).

3 Rede Municipal, Rede Estadual e Rede Privada de Ensino.

4 "Cada uma das cidades foi considerada como um estrato e, dentro de cada cidade, foi selecionada uma amostra probabilística complexa de escolas, turmas e alunos a partir do cadastro do Censo Escolar de 2003, excluídas as escolas que não possuíam 10 alunos ou mais matriculados no $2^{\circ}$ ano do ensino fundamental (ou seu equivalente em ciclos)" (Franco; Brooke; Alves, 2008, p. 630).

5 Uma caracterização mais pormenorizada e suas implicações para o funcionamento das escolas pesquisadas foi desenvolvida em trabalho anterior (Betini; Almeida; Malavasi, 2012).

6 Os valores do NSE são normalizados com média zero e desvio padrão 1. Isso significa que os valores podem oscilar de $-3 \mathrm{a}+3$, no entanto aproximadamente $68 \%$ das escolas encontram-se entre -1 e 1.

7 Pelo conteúdo das respostas abarcarem, por vezes, mais de um núcleo de conteúdo, algumas delas foram classificadas em mais de uma temática analítica.

8 Em decorrência do objetivo de nosso estudo optamos por textualizar as declarações de forma a proceder a pequenas correções de concordância e ortografia que fossem necessárias, não alterando, todavia, o sentido da redação. Tudo o que necessitamos incluir por omissão na construção das frases está destacado entre colchetes.

\section{Referências}

ALBUQUERQUE, Simone Santos. A participação das famílias como uma política educativa. Educação, Santa Maria, v. 39, n. 3, p. 617-628, set./dez. 2014. 
ALMEIDA, Luana Costa. Relação entre o Desempenho e o Entorno Social em Escolas Municipais de Campinas: a voz dos sujeitos. 2014. $326 \mathrm{f}$. Tese (Doutorado em Educação) -Universidade Estadual de Campinas, Campinas, 2014.

ALMEIDA, Luana Costa; BETINI, Geraldo Antônio. Investigação sobre a escola e seu entorno: Estudo bibliográfico de produções nacionais. Revista de Educação Pública, Cuiabá, UFMT, v. 24, n. 55, p. 33-56, jan./abr. 2015.

ALVES, Maria Teresa Gonzaga; SOARES, José Francisco. Medidas de nível socioeconômico em pesquisas sociais: uma aplicação aos dados de uma pesquisa educacional. Opin. Publica, Campinas, v. 15, n. 1, p. 1-30, jun. 2009.

ARROYO, Miguel Gonzáles. Políticas educacionais e desigualdades: à procura de novos significados. Educação e Sociedade, Campinas, v. 31, n. 113, p. 13811416, out./dez. 2010.

BARBOSA, Maria Ligia de Oliveira; SANT'ANNA, Maria Josefina Gabriel. As classes populares e a valorização da educação no Brasil. Seminário Nacional Governança Urbana e Desenvolvimento Metropolitano, 2010, Natal. Anais... Natal: 2010

BETINI, Geraldo Antônio; ALMEIDA, Luana Costa. Relatório das Visitas às Escolas que Serão Pesquisadas pelo Projeto Observatório Eixo 2 - Escola e Comunidade. LOED, 2010.

BETINI, Geraldo Antônio; ALMEIDA, Luana Costa; MALAVASI, Maria Marcia Sigrist. Escola e Comunidade: Primeiras aproximações. In: FREITAS, Luiz Carlos et al. (Org.). Avaliação e Políticas Públicas Educacionais: ensaios contrarregulatórios em debate. Campinas, SP: Edições Leitura Crítica, 2012. P. 227-248.

CASTRO, Jane Margareth; REGATTIERI, Marilza (Org.). Interação Escola-Família: subsídios para práticas escolares. Brasília: UNESCO; MEC, 2009.

COLEMAN, James Samuel et al. Equality of Educational Opportunity. Washington: Office of Education and Welfare, 1966.

DALBEN, Adilson. Fatores Associados à Proficiência em Leitura e Matemática: uma aplicação do modelo linear hierárquico com dados longitudinais do Projeto GERES. 2014. 482 f. Tese (Doutorado em Educação) - Universidade Estadual de Campinas, Campinas, 2014.

DAYRELL, Juarez. Família, Escola e Juventude: olhares cruzados Brasil-Portugal. Belo Horizonte: Editora UFMG, 2012.

FRANCO, Creso; BROOKE, Nigel; ALVES, Fátima. Estudo longitudinal sobre qualidade e equidade no ensino fundamental brasileiro: GERES 2005. Ensaio: Avaliação, Política Pública e Educação, Rio de Janeiro, v. 16, n. 61, p. 625-638, dez. 2008.

GROLNICK, Wendy; SLOWIACZEK, Maria L. Parents' involvement in children's schooling: a multidimensional conceptualization and motivation model. Child Development, University of Michigan, v. 65, n. 1, p. 237-252. 1994.

LAHIRE, Bernard. Sucesso Escolar nos Meios Populares: as razões do improvável. São Paulo: Ática, 1997.

LOMONACO, Beatriz Penteado; GARRAFA, Thais Christofe. A complexidade da relação escola-família em territórios vulneráveis. Cadernos Cenpec, nova série, [S.l.], São Paulo, v. 4, n. 6, p. 27-38, jun. 2009. Disponível em: <http://cadernos.cenpec.org.br/cadernos/index.php/cadernos/article/view/21>. Acesso: jan. 2010. 
MAGALHÃES, Cleidilene Ramos. Escola e Família: mundos que se falam? - Um estudo no contexto da implementação da Progressão Continuada. 437 f. 2004. Tese (Doutorado em Educação) - Universidade Federal de São Carlos, São Carlos, 2004.

MALAVASI, Maria Marcia Sigrist et al. A voz das famílias no Contexto Escolar: contribuições para pensar a qualidade negociada. In: FREITAS, Luiz Carlos et al. (Org.). Avaliação e Políticas Públicas Educacionais: ensaios contrarregulatórios em debate. Campinas, SP: Edições Leitura Crítica, 2012. P. 249-262.

MÜLLER, Maria Lúcia Rodrigues; PAIXÃO, Lea Pinheiro (Org.). Educação, Diferenças e Desigualdades. Cuiabá: EdUFMT, 2006.

NOGUEIRA, Maria Alice. Família e escola na contemporaneidade: os meandros de uma relação. Educação \& Realidade, Porto Alegre, FACED UFRGS, v. 31. n. 02, p. 155-169, jul./dez. 2006.

NOGUEIRA, Cláudio Marques Martins et al. A influência da família no desempenho escolar: estudo de dados da Geração Escolar 2005. Revista Contemporânea de Educação, Belo Horizonte, v. 4, n. 8, p. 379-396, 2009.

OLIVEIRA, Cynthia Bisinoto Evangelista; MARINHO-ARAUJO, Claisy Maria. A relação família-escola: intersecções e desafios. Estudos de Psicologia, Campinas, v. 27, n. 1, p. 99-108, jan./mar. 2010.

PAIXÃO, Lea Pinheiro. Compreendendo a escola na perspectiva das famílias. In: MÜLLER, Maria Lúcia Rodrigues; PAIXÃO, Lea Pinheiro (Org.). Educação, Diferenças e Desigualdades. Cuiabá: EdUFMT, 2006.

PINTO, Fátima Cunha Ferreira; GARCIA, Vanessa Coelho; LETICHEVSKY, Ana Carolina. Pesquisa Nacional Qualidade na Educação: a escola pública na opinião dos pais. Ensaio: Avaliação, Política Pública e Educação, Rio de Janeiro, v. 14, n. 53, p. 527-542, out./dez. 2006.

REALI, Aline Maria de Medeiros Rodrigues; TANCREDI, Regina Maria Simões Puccinelli. A importância do que se aprende na escola: a parceria escola-famílias em perspectiva. Paidéia (Ribeirão Preto), Ribeirão Preto, v. 15, n. 31, ago. 2005.

RIBEIRO, Daniela de Figueiredo; ANDRADE, Antonio dos Santos. A assimetria na relação entre família e escola pública. Paidéia, Ribeirão Preto, v. 16, n. 35, p. 385-394, dez. 2006.

SOLIS, Patrício. Efeitos do nível socioeconômico da vizinhança na continuidade escolar entre o Ensino Médio e o Pré-universitário no México, Distrito Federal. In: RIBEIRO, Luiz Cesar Queiroz; KAZTMAN, Ruben (Org.). A Cidade Contra a Escola?: segregação urbana e desigualdades educacionais em grandes cidades da América Latina. Rio de Janeiro: Letra Capital, FAPERJ; Montevidéu; Uruguai: IPPES, 2008.

THIN, Daniel. Famílias de camadas populares e a escola: confrontação desigual de modos de socialização. In: MÜLLER, Maria Lúcia Rodrigues; PAIXÃO, Lea Pinheiro (Org.). Educação, Diferenças e Desigualdades. Cuiabá: EdUFMT, 2006.

THIN, Daniel. Para uma análise das relações entre famílias populares e escola: confrontação entre lógicas socializadoras. Revista Brasileira de Educação, Rio de Janeiro, v. 11, n. 32, p. 211-225, maio/ago, 2006b.

TRAVITZKI, Rodrigo. ENEM: limites e possibilidades do Exame Nacional do Ensino Médio enquanto indicar de qualidade escolar. 322 f. 2013. Tese (Doutorado em Educação) - Faculdade de Educação, Universidade de São Paulo, São Paulo, 2013. Disponível em: <http://www.teses.usp.br/teses/disponiveis/48/48134/ tde-28062013-162014/pt-br.php>. Acesso em: jul. 2013.

670 Educação \& Realidade, Porto Alegre, v. 42, n. 2, p. 649-671, abr./jun. 2017. 
VIANA, Maria Jose Braga. Longevidade escolar em famílias de camadas populares - algumas condições de possibilidade. In: NOGUEIRA, Maria Alice; ROMANELLI, Geraldo; ZAGO, Nadir (Org.). Família \& Escola: trajetórias de escolarização em camadas médias e populares. Petrópolis: Vozes, 2000. P. 45-60.

ZAGO, Nadir. A relação escola-família nos meios populares: apontamentos de um itinerário de pesquisas. In: DAYRELL, Juarez. Família, Escola e Juventude: olhares cruzados Brasil-Portugal. Belo Horizonte: Editora UFMG, 2012. P. 132150 .

ZAGO, Nadir. Processos de escolarização nos meios populares - as contradições da obrigatoriedade escolar. In: NOGUEIRA, Maria Alice; ROMANELLI, Geraldo; ZAGO, Nadir (Org.). Família \& Escola: trajetórias de escolarização em camadas médias e populares. Petrópolis: Vozes, 2000. P. 17-44.

Luana Costa Almeida é doutora em Educação (2014) pela Universidade Estadual de Campinas (UNICAMP), com período de estágio na Universidade Autônoma de Barcelona (UAB). Possui graduação em Pedagogia (2004); mestrado em Educação (2008) ambos pela UNICAMP e pós-doutorado (2015) pelo Centro de Estudos da Metrópole (CEM-Cebrap). Atualmente é professora do Mestrado em Educação da Universidade do Vale do Sapucaí (UNIVAS) e pesquisadora colaboradora no Laboratório de Observação e Estudos Descritivos (LOED).

E-mail: luanaca@gmail.com

Luana Ferrarotto é doutoranda em Educação, vinculada ao Laboratório de Observação e Estudos Descritivos (LOED), na Universidade Estadual de Campinas (UNICAMP). Possui graduação em Pedagogia (2005) e Mestrado em Educação (2011) ambos pela UNICAMP. Atualmente é professora do Instituto Federal de Educação, Ciência e Tecnologia de São Paulo, campus Bragança Paulista.

E-mail: luanaferrarotto@yahoo.com.br

Maria Marcia Sigrist Malavasi é doutora em Educação (2000) pela Universidade Estadual de Campinas (UNICAMP). Possui graduação em História pela UNICAMP (1979), graduação em Pedagogia pela Universidade Nove de Julho (1990), mestrado em Educação pela UNICAMP (1995) e pós-doutorado pela Universidade do Porto (2016). Atualmente é professora da Universidade Estadual de Campinas e pesquisadora no Laboratório de Observação e Estudos Descritivos (LOED).

E-mail:mmarcia@unicamp.br 